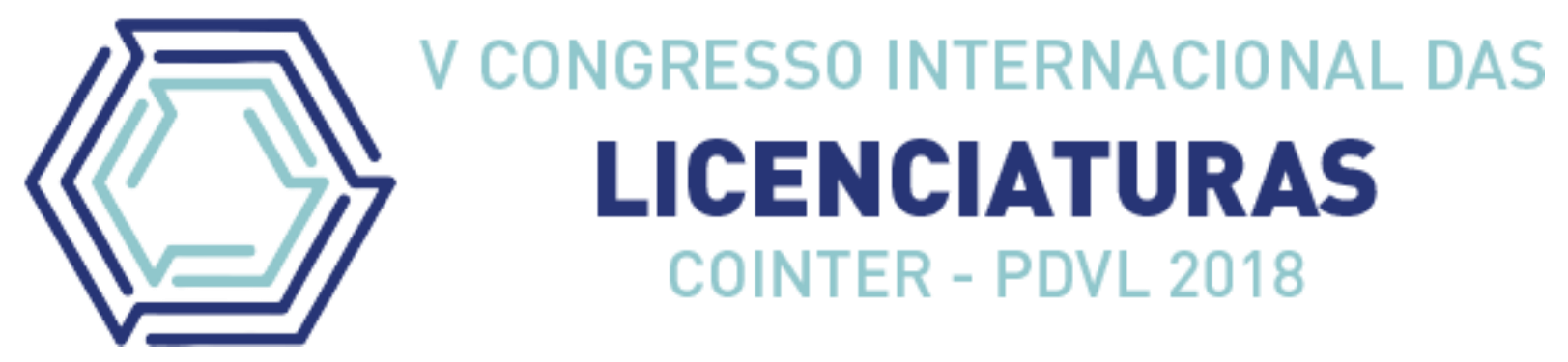

\title{
SITUAÇÕES DIDÁTICAS: A APLICAÇÃO DO TANGRAM OVAL NO ENSINO DE ÂNGULOS NO $6^{\circ}$ ANO DO ENSINO FUNDAMENTAL
}

\author{
DIDACTIC SITUATIONS: THE APPLICATION OF OVAL TANGRAM IN THE \\ EDUCATION OF ANGLES IN THE 6th YEAR OF FUNDAMENTAL EDUCATION
}

\author{
Apresentação: Comunicação Oral \\ Rosana Maria da Silva'; Vânia de Moura Barbosa Duarte ${ }^{2}$ \\ DOI: https://doi.org/10.31692/2358-9728.VCOINTERPDVL.2018.00147
}

\begin{abstract}
Resumo
O ensino de matemática vem sofrendo modificações, mais especificamente em relação ao conceito de ângulos, essas modificações se tornam necessárias para que os estudantes possam construir uma aprendizagem com significados. Uma das possibilidades é propor a Teoria das Situações Didáticas na prática pedagógica, pois promove a interação entre professor, aluno e saber. Desta forma, o problema que norteia esse estudo é: de que forma a Teoria das Situações Didáticas com o auxílio do Tangram Oval podem contribuir no ensino de conceitos de ângulos no $6^{\circ}$ ano do Ensino Fundamental? Diante do exposto o trabalho em questão teve por objetivo promover o ensino de conceitos de ângulos através de situações didáticas com o auxílio do Tangram Oval no $6^{\circ}$ ano do Ensino Fundamental. A pesquisa foi desenvolvida com alunos do $6^{\circ}$ ano de uma escola da rede pública municipal da cidade de Passira-PE, ocorrendo em três momentos: a primeira aplicação do teste de sondagem, a vivência de uma Situação Didática e a segunda aplicação do teste de sondagem. Essa metodologia permitiu que os estudantes desenvolvessem habilidades como o uso do transferidor e do compasso. Os resultados obtidos indicam que os estudantes obtiveram um melhor percentual no reconhecimento do transferidor como instrumento de medida de ângulos e identificaram a conservação dos ângulos nas figuras. A intervenção através de uma situação didática proporcionou durante a construção do jogo o desenvolvimento da autonomia, a responsabilidade pela própria construção do conhecimento, a percepção da aplicação matemática no meio social, a compreensão dos conhecimentos matemáticos presentes na construção.
\end{abstract}

Palavras-Chave: Ensino de ângulos, Teoria das Situações Didáticas, Tangram Oval.

\footnotetext{
Abstract

The teaching of mathematics has suffered modifications, more specifically in relation to the concept of angles, these modifications become necessary to the student can build na learning with meanings.

${ }^{1}$ Licenciatura em Matemática, Universidade de Pernambuco, rosanamaria386@gmail.com

2 Mestre, Universidade de Pernambuco, vania.duarte@upe.br
} 
One of the possibilities is to propose the Theory of Didactic Situations that promotes the interaction between teacher, pupil and knowledge. In this way, the problem that guides this study is: how does the Theory of Didactic Situations with the help of the Oval Tangram can contribute in teaching the concepts of angles in the 6th year of Basic Education? In view of the foregoing the work in question was aimed at promoting the teaching of concepts of angles through didactic situations with the help of the Oval Tangram in the 6th year of elementary School. The research was developed with students of the 6th year in a public school municipal in the city of Passira-PE, occurring in three moments: the first application of probing test, the experience of a situation didactics and the second application of the probing test. This methodology allowed the students to develop skills as the use of the protractor and compass. The results obtained indicate that students have a better percentage in the recognition of the protractor as na instrument to measure angles and identified the conservation of the angles in the figures. The intervention through a didactic situation provided during the construction of the game the development of autonomy, responsibility for the actual construction of knowledge, the perception of applying mathematics in the social environment, the understanding of mathematical knowledge present in the construction.

Keywords: Teaching angles, Theory of Didactic Situations, Oval Tangram..

\section{Introdução}

O ensino de matemática vem sofrendo modificações, isto se deve ao fato de que esta disciplina apresenta no contexto escolar altos índices de reprovação, consequência do ensino tradicional, em que muitas vezes a disciplina é apresentada de forma incoerente. Esse tipo de metodologia propõe a repetição de modelos matemáticos e a memorização destes, neste sentido o estudante dificilmente conseguirá relacionar os conteúdos à vida social. No entanto, como propõe a Lei de Diretrizes e Bases - LDB (1996), a educação precisa se relacionar com as práticas sociais, onde o estudante utilize o conhecimento adquirido na escola para compreender situações fora dela. Assim, no ensino de matemática o conteúdo deve ser apresentado de modo que o educando compreenda a importância de entender e relacionar os conteúdos entre teoria e prática.

No $6^{\circ}$ ano do Ensino Fundamental é comum encontrarmos estudantes com dificuldades em vários conceitos matemáticos, principalmente no que diz respeito ao campo geométrico, pois devido ao grande número de conteúdos este muitas vezes é deixado de lado. No que diz respeito a ângulos não é diferente, muitos alunos chegam aos anos finais do Ensino Fundamental sem ter visto o conteúdo, ou então com uma breve noção sobre o mesmo. No entanto, este é apresentado inicialmente no $4^{\circ}$ ano do ensino Fundamental e sua ampliação é proposta nos demais anos.

Por diversas vezes os alunos resolvem determinadas operações envolvendo ângulos, 
porém não conseguem definí-lo ou até mesmo aplicá-lo em outra situação. Faz-se necessário utilizar uma metodologia que proporcione autonomia e possibilite ao estudante, por meio de intervenções, a construção do conhecimento de forma crítica e satisfatória.

Utilizou-se a Teoria das Situações Didáticas (TSD). Para que esta seja executada, é necessário que haja a relação entre professor, aluno e saber, de forma que o professor seja um mediador, buscando estratégias para que o aluno construa o conhecimento. Através da TSD é possível que o estudante seja apresentado ao problema e procure solucioná-lo, elaborando estratégias para resolvê-lo. Para apresentar o Saber, é possível utilizar-se de materiais concretos, como é o caso dos jogos, estes são interessantes, pois além de seus aspectos próprios, como a ludicidade e a presença no meio social, também pode ser explorado como uma ferramenta didática.

Nessa perspectiva, utilizou-se o jogo Tangram Oval (TO), que é pouco explorado como recurso didático, mas que pode ser um grande aliado no ensino de geometria. Sua construção evidencia muitos conceitos geométricos, que partem do uso do compasso e da régua para suas diferentes peças, que podem ser separadas através das diferentes características apresentadas. Assim, de que forma a Teoria das Situações Didáticas, com o auxílio do Tangram Oval, pode contribuir no ensino dos conceitos de ângulos no $6^{\circ}$ ano do Ensino Fundamental?

O ensino de ângulos, ao ser proposto em uma situação didática, com o auxílio do TO pode contribuir para a construção de uma compreensão crítica e reflexiva do conteúdo. Nesse contexto, nosso principal objetivo foi promover o ensino de conceitos de ângulos através de situações didáticas com o auxílio do Tangram Oval no $6^{\circ}$ ano do Ensino Fundamental.

\section{Fundamentação Teórica}

A Teoria das Situações Didáticas foi proposta por Guy Brousseau, sendo definida como,

O conjunto de relações estabelecidas explicitamente e/ou implicitamente entre um aluno ou grupo de alunos, um certo milieu (contendo eventualmente instrumentos ou objetos) e um sistema educativo (o professor) para que esses alunos adquiram um saber constituído ou em constituição. (BROUSSEAU, 1978, apud ALMOULOUD, 2007, p.33)

Cada um desses elementos são de suma importância para o processo de aprendizagem, pois cada um tem um papel essencial. O professor é caracterizado como mediador, buscando estratégias para que os alunos aprendam, o milieu (meio) é utilizado para apresentar o saber, enquanto que o aluno constrói o conhecimento a partir das mediações realizadas. 
O papel do professor vai além da construção de conhecimento apenas para uso na sala de aula, ou seja, "a intervenção do professor evoca, necessariamente, em relação aos conhecimentos que ensina, um funcionamento possível em outras circunstâncias" (BROUSSEAU, 2008, p. 54), de maneira que o conhecimento aprendido em sala é posto em prática no contexto social, onde não há interferência do professor.

Para resolução de um problema Brousseau apresenta cinco fases, a primeira de devolução que é caracterizada nas interações entre os alunos e os problemas colocados pelo professor em uma situação didática, em que "deve ter por objetivo provocar uma interação que permita ao aluno desenvolvimento autônomo" (ALMOULOUD, 2007, p.34). Nessa etapa o estudante assume responsabilidade por sua aprendizagem e suas consequências, com vista a elaborar estratégias corretas para resolução do problema.

A segunda etapa é definida como ação, que se caracteriza por colocar um problema para o aluno para que ele possa agir sobre essa situação e que ela atribua informações sobre sua ação. A terceira etapa é a de formulação que consiste em proporcionar ao aluno condições para que este construa, progressivamente, uma linguagem compreensível por todos, que considere os objetos e as relações matemáticas envolvidas na situação adidática. A quarta etapa é a de validação na qual o aprendiz deve mostrar a validade do modelo por ele criado, submetendo a mensagem matemática ao julgamento de um interlocutor. A quinta etapa é a de institucionalização que, foram então definidas como aquelas em que o professor fixa convencionalmente e explicitamente o estatuto cognitivo do saber (ALMOULOUD, 2007).

Nos anos finais do Ensino Fundamental, de acordo com a Base Nacional Comum Curricular (BRASIL, 2017) o ensino de geometria precisa ser visto como a consolidação e ampliação das aprendizagens realizadas, ou seja, o que foi aprendido será utilizado para facilitar a compreensão do novo conhecimento, partindo para a ampliação do conceito e não se reduzindo a mera repetição de fórmulas.

A primeira vez em que o conteúdo de ângulos aparece como expectativa nos Parâmetros Curriculares para a Educação Básica do Estado de Pernambuco - PCPE é no $4^{\circ}$ ano do ensino fundamental, com o objetivo de "reconhecer ângulos retos" (PERNAMBUCO, p.55, 2012). Tal conteúdo é de suma importância para a compreensão de diversos aspectos da Geometria e é apresentado nesse ano de escolarização a partir de figuras geométricas, o que facilita o entendimento.

No $6^{\circ}$ ano, podemos destacar uma das expectativas no campo das grandezas e medidas 
em relação aos ângulos, que seria "reconhecer ângulo como grandeza, identificando o transferidor como instrumento de medição, e o grau, como unidade." (PERNAMBUCO, 2012, p.108). Nessa etapa, o estudante já compreende o conceito, mas ainda não o entende como grandeza, o uso do transferidor facilitará esse entendimento.

No estudo da geometria utilizar recursos como régua, compasso e transferidor é importante, pois os alunos desenvolverão algumas habilidades como construir figuras planas e compreender suas medidas, de modo a ampliar as possibilidades de construções geométricas (MAZIERO, 2011).

Ainda no $6^{\circ}$ ano podemos destacar uma das expectativas que se refere ao ângulo no campo geométrico, que é "reconhecer, em situações de ampliação e redução, a conservação dos ângulos e a proporcionalidade entre os lados de figuras poligonais.” (PERNAMBUCO, 2012, p.94). Neste caso, o aluno deverá perceber que em figuras semelhantes os ângulos não se alteram, mesmo que os tamanhos sejam diferentes.

A utilização dos jogos como recurso didático pode contribuir na compreensão de conceitos matemáticos, mas é necessário verificar os objetivos a serem alcançados. O jogo pode ser entregue pronto ou confeccionado pelos estudantes na própria sala de aula, neste contexto “[...] o material mais adequado, nem sempre, será o visualmente mais bonito e nem o já construído. Muitas vezes, durante a construção de um material, o aluno tem a oportunidade de aprender matemática de uma forma mais efetiva." (FIORENTINI E MIORIM, 1990, p.6).

Partindo desse princípio, utilizaremos o Tangram Oval (TO), que é um jogo (figura 1) que pode ser construído pelos estudantes na sala de aula. $\mathrm{O}$ objetivo do jogo é montar figuras de forma que não se sobreponham as peças, com ele é possível formar 95 figuras diferentes. $\mathrm{O}$ TO permite o desenvolvimento da criatividade, o uso do compasso, da régua, a identificação das figuras geométricas presentes no jogo, a autonomia e o trabalho em equipe.

Figura 1-Tangram Oval. Fonte: http://matheusmathica.blogspot.com/2009/12/tangram-oval.html

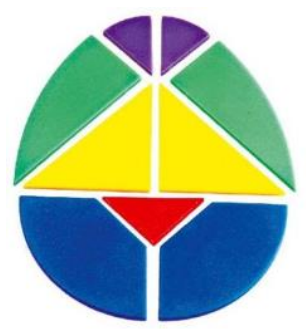

Esse tipo de tangram é pouco trabalhado e investigado em sala de aula. No entanto suas partes curvadas permitem explorar outros aspectos da geometria, que surgem a cada passo da construção. Desse modo Gonçalves (2013) corrobora, 
também chamado de ovo mágico e ovo de Colombo, o Tangram Oval propõe a construção de figuras a partir de um número limitado de peças. Ao contrário do Tangram Clássico, o Tangram Oval contém peças com bordas curvas, o que resulta em figuras com contornos mais suaves. (Gonçalves, 2013, p.6)

Essas características do TO favorecem o seu uso em sala de aula. Sua composição se dá a partir de nove figuras geométricas, são elas: dois triângulos isósceles curvos; dois triângulos retângulos curvos; dois triângulos retângulos grandes; um triângulo retângulo pequeno; dois trapézios curvos. Além deste Tangram, existem outros tipos como: o tangram pitagórico, o tangram de nove peças, o tangram retangular, o tangram coração partido e o tangram circular.

\section{Metodologia}

A fim de propor uma situação didática para o ensino de ângulos, utilizando o tangram oval e considerando os objetivos que se tem nessa pesquisa, optamos por uma metodologia de abordagem qualitativa de tipo estudo de caso. Segundo Godoy (1995) a pesquisa qualitativa precisa ser analisada em uma perspectiva integrada, de forma que o fenômeno possa ser mais bem compreendido no contexto em que ocorre e do qual é parte. Dessa maneira, a análise dos dados da pesquisa busca interpretar os resultados e não apenas quantificar.

O presente trabalho foi proposto para uma turma do $6^{\circ}$ ano do Ensino Fundamental, em uma escola da rede pública de ensino da cidade de Passira-PE. A escolha pelo local se deu através do componente curricular estágio supervisionado realizado na escola, em que foi notada uma carência em relação ao ensino de ângulos. Participaram da pesquisa 28 alunos do $6^{\circ}$ ano do ensino fundamental.

A pesquisa se desenvolveu a partir de uma sequência didática, dividida em três momentos: no primeiro momento a aplicação de um teste de sondagem para analisar os conhecimentos dos alunos em relação aos conceitos geométricos necessários para a construção do jogo Tangram Oval e compreensão do conceito de ângulos; no segundo momento a construção da Situação Didática com o auxílio do Tangram Oval composta das seguintes etapas:

$1^{\mathrm{a}}$ etapa (devolução): Construção do jogo Tangram Oval pelos alunos.

$2^{\mathrm{a}}$ etapa (ação): Identificação do instrumento correto para medir a abertura do ângulo Î do triângulo JHI presente no jogo (pelos alunos), em seguida foi realizada a comparação da medida encontrada com a medida do ângulo CÔA. 
$3^{\text {a }}$ etapa (formulação): Elaboração de argumentos que justifiquem o uso do transferidor na medição de ângulos encontrados (pelos alunos) nas figuras presentes no jogo, além de argumentar sobre a conservação destes.

$4^{\mathrm{a}}$ etapa (validação): Apresentação das resoluções e argumentações dos alunos, buscando convencer a turma da veracidade dos resultados obtidos.

$5^{\mathrm{a}}$ etapa (institucionalização): Institucionalização do saber construído pelos estudantes a partir da construção do jogo, em que o professor estabelece um caráter objetivo e generalizado do conhecimento apresentado pelos alunos na etapa anterior. No terceiro momento a análise da situação vivenciada por meio do mesmo teste de sondagem aplicado, a fim de analisar a evolução conceitual dos estudantes.

Inicialmente propomos um teste de sondagem no intuito de analisar os conhecimentos prévios dos alunos. Composto por seis questões, destas, quatro subjetivas e duas objetivas. As mesmas foram elencadas de acordo com os conteúdos necessários para a compreensão de ângulos e construção do jogo.

Após a aplicação do teste de sondagem, foi realizada uma retomada dos conceitos para a compreensão na construção do jogo. Inicialmente foram apresentados alguns aspectos pertencentes à construção do TO, que são: as diferenças e semelhanças entre um círculo e uma circunferência; as características de uma circunferência, denotando raio, diâmetro e arco; os segmentos de reta e o desenho da circunferência com o uso do compasso. A turma apresentou dificuldades no manuseio do compasso, em que foram necessárias várias construções de circunferências para que pudessem se familiarizar. Além disso, foram expostas as noções de ângulos conforme estabelecido para o $5^{\circ}$ ano, no intuito de que o aluno recordasse o conceito de maneira a compreender a situação a ser proposta posteriormente.

Para a construção do jogo os alunos utilizaram o compasso e a régua, foi utilizado papel pontilhado para que o desenho se aproximasse o máximo possível da construção do jogo apresentado. Após construção, os estudantes receberam uma ficha de apoio, composta por três questões. A primeira sugeria que os alunos medissem o ângulo HÎJ do triângulo HJI presente na figura construída (figura 2). Assim, os alunos deveriam elaborar estratégias para solucionar o problema. Já na segunda questão os estudantes deveriam indicar o instrumento utilizado para responder a questão anterior. A terceira questão indicava a comparação entre o ângulo HÎJ e o ângulo CÔA, de forma que ao fazer essa confrontação pudessem perceber que os ângulos mantinham a mesma medida, apesar de sua ampliação. 
Figura 7 - Ângulos analisados na Situação Didática. Fonte:

http://oserprofessora.blogspot.com.br/2010/04/tangram-oval.html

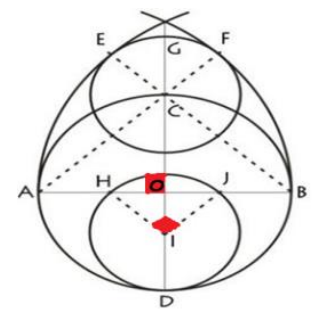

Após vivência da situação didática propomos a reaplicação do teste de sondagem com vista a analisar os avanços conceituais dos estudantes.

\section{Resultados e Discussão}

Os dados obtidos na primeira aplicação do teste de sondagem foram sintetizados no quadro 1, sendo divididos em três categorias: conceitos relacionados a construção, conceitos relacionados a anos anteriores e conceitos a serem construídos. As duas primeiras questões se referiram aos conhecimentos necessários para a construção do jogo, abordando o uso do compasso e da régua, assim como ao entendimento de circunferência (inclusas as ideias de raio, diâmetro e arco). A terceira e quarta questões abordaram os conceitos já estudados em anos anteriores relacionados aos conceitos de segmento de reta e de ângulos. As questões cinco e seis se referiram aos conhecimentos a serem construídos no $6^{\circ}$ ano, sendo abordado o reconhecimento do transferidor como instrumento de medida e a identificação da conservação dos ângulos.

Quadro 1 - Resultados da primeira aplicação do teste de sondagem. Fonte: Própria

\begin{tabular}{|l|l|l|l|l|l|}
\hline $\begin{array}{l}\text { Conceitos referentes a } \\
\text { construção do jogo }\end{array}$ & \multicolumn{2}{|l|}{$\begin{array}{l}\text { Conceitos já estudados em } \\
\text { anos anteriores }\end{array}$} & \multicolumn{2}{l|}{$\begin{array}{l}\text { Conceitos a serem construídos a } \\
\text { partir da construção do jogo }\end{array}$} \\
\hline Compasso & Circunferência & $\begin{array}{l}\text { Segmentos de Ângulos } \\
\text { reta }\end{array}$ & $\begin{array}{l}\text { Reconhecimento do } \\
\text { transferidor como } \\
\text { instrumento de } \\
\text { medida }\end{array}$ & $\begin{array}{l}\text { Conservação } \\
\text { dos ângulos }\end{array}$ \\
\hline $10,7 \%$ & $0 \%$ & $92,8 \%$ & $7,1 \%$ & $7,1 \%$ & $32,1 \%$ \\
\hline
\end{tabular}

Dos 28 alunos investigados apenas 10, 7\% já haviam utilizado o compasso, desse modo as respostam indicam que os demais estudantes nunca utilizaram o compasso, no entanto, apesar de não ser proposta pelos parâmetros nesse ano de escolaridade, sua utilização é de grande importância. De acordo com Maziero (2011) não utilizar esse tipo de ferramenta 
compromete a compreensão do aluno em relação à construção de figuras, podendo interferir no processo de aprendizagem.

Em relação aos segmentos de reta obtivemos um maior número de respostas corretas, cerca de $92,8 \%$, ao considerar que o conteúdo tenha sido visto nos anos anteriores, podemos dizer que esse percentual foi resultado do ensino realizado de maneira a promover uma aprendizagem com significados (BROUSSEAU, 2008).

Com relação aos conceitos de ângulos, cerca de 7,1\% apresentaram respostas sobre o entendimento do conceito. Apesar de ser proposto pelo PCPE (PERNAMBUCO, 2012) desde o $4^{\circ}$ ano, podemos perceber que poucos alunos demonstraram conhecimento em relação ao conceito. No que tange ao uso do transferidor o percentual foi o mesmo, o que indica a utilização da ferramenta apenas pelos estudantes que demonstraram compreensão sobre o conceito de ângulos.

A questão em relação à conservação dos ângulos apresentou $32,1 \%$, neste caso os alunos identificaram a ampliação da figura poligonal. Para solucionar a questão os alunos consideraram a proporção entre os lados da figura e principalmente a conservação dos ângulos internos que foi o fator determinante para a resolução da questão. Apesar de ter sido proposto no $5^{\circ}$ ano, poucos alunos acertaram a questão (PERNAMBUCO, 2012).

Na situação didática consideramos as cinco etapas propostas por Brousseau (2008). Na etapa de devolução foi possível identificar o empenho dos estudantes em construir corretamente o jogo. Essa atividade desenvolveu a criatividade, a autonomia e atraiu a atenção dos estudantes, com isso constatamos que a construção de materiais concretos pode contribuir para uma aprendizagem de matemática mais efetiva. De acordo com Fiorentini e Miorim (1990) durante a construção de um jogo, muitas vezes o aluno tem oportunidade de aprender matemática de forma mais efetiva.

A segunda etapa foi caracterizada como sendo uma situação de ação, em que os alunos ficaram diante do problema e buscaram elaborar estratégias para resolvê-lo. Nesse contexto a turma foi dividida em trios e cada equipe recebeu uma ficha de apoio com dois problemas propostos, a divisão da turma em grupos se deu baseado na proposta do jogo "Quem vai dizer 20?” de Brousseau (2008) em que a troca de opiniões também faz parte da situação.

$\mathrm{Na}$ etapa de formulação, uma das equipes, aqui caracterizada por equipe 1 (figura 3), reconheceu que o transferidor seria o instrumento correto para medir ângulos e na justificativa a equipe relatou que o formato de circunferência do transferidor teria determinado a medição 
do ângulo, neste sentido, os estudantes verificaram os graus no instrumento e associaram como sendo uma unidade de medida. Como proposto pelo PCPE (PERNAMBUCO, 2012), além de reconhecer o transferidor como instrumento de medida, a equipe compreendeu os ângulos como uma grandeza.

Figura 3- Resposta em relação ao uso do transferidor. Fonte: Própria.

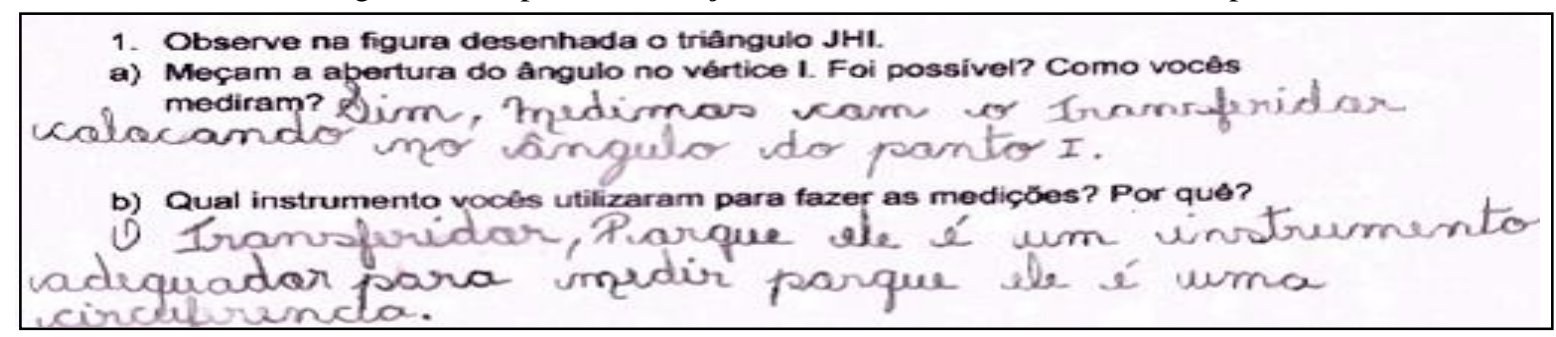

Na etapa de validação, assim como é proposto por Almouloud (2007) os estudantes fizeram uma exposição aos demais colegas das estratégias utilizadas para responder as questões. Nesse momento os estudantes apresentaram suas argumentações, buscando convencer a turma a respeito de suas afirmações. A última etapa da situação didática foi caracterizada como sendo de institucionalização, sendo proposta baseada nos conhecimentos apresentados em que os conhecimentos pessoais e individuais foram generalizados ao saber científico.

Para análise da situação vivenciada propomos o mesmo teste de sondagem, com o intuito de analisar os avanços conceituais dos educandos, o quadro abaixo sintetiza os resultados das aplicações (quadro 2) . Consideramos não apenas o conceito de ângulos, mas também os conhecimentos prévios inerentes ao jogo e que podem auxiliar na compreensão do conceito.

Quadro 2 - Comparativo entre a primeira e a segunda aplicação do teste de sondagem. Fonte: Própria.

\begin{tabular}{|l|l|l|}
\hline \multicolumn{2}{|l|}{ Dados (\%) obtidos na $1^{\mathrm{a}}$ e $2^{\mathrm{a}}$ aplicação do teste de sondagem } \\
\hline Questões & $1^{\circ}$ teste de sondagem & $2^{\circ}$ teste de sondagem \\
\hline $2^{\mathrm{a}}$ & $0 \%$ & $39,2 \%$ \\
\hline $3^{\mathrm{a}}$ & $92,8 \%$ & $100 \%$ \\
\hline $4^{\mathrm{a}}$ & $7,1 \%$ & $21,4 \%$ \\
\hline $5^{\mathrm{a}}$ & $7,1 \%$ & $71,4 \%$ \\
\hline
\end{tabular}




\begin{tabular}{|l|l|l|}
\hline $6^{\mathrm{a}}$ & $32,1 \%$ & $46,4 \%$ \\
\hline
\end{tabular}

Ao realizar esse comparativo percebemos que em relação a questões com os conteúdos aplicados os estudantes apresentaram maior desempenho, não obstante em relação a questões que exigiam escrita de raciocínios e definição percebemos um pequeno avanço. A aprendizagem matemática, assim como em qualquer disciplina, se dá na interação entre teoria e prática, observamos um avanço considerável em relação a primeira aplicação do teste. Os estudantes apresentaram mais segurança ao responder as questões relacionadas à construção do jogo e principalmente em relação à conservação de ângulos e ao uso do transferidor.

\section{Conclusões}

A proposta de construção do tangram oval se mostrou eficaz no ensino de ângulos, tendo em vista que possibilitou ao estudante identificar os ângulos em diferentes aplicações e a compreensão do conceito como uma grandeza, sendo possível medi-lo com o transferidor. Ressaltamos também, que o uso desse instrumento é muito pertinente no estudo de ângulos e que são propostos nos demais anos do ensino básico.

A proposta de intervenção através de uma situação didática proporcionou durante a construção do jogo o desenvolvimento da autonomia, a responsabilidade pela própria construção do conhecimento, a percepção da aplicação matemática no meio social, a compreensão dos conhecimentos matemáticos presentes na construção. Enquanto que o trabalho em equipe permitiu socialização, espírito de liderança e partilha dos conhecimentos que também contribuiu na construção do conceito, além do desenvolvimento do pensamento crítico.

Por meio dessa situação didática foi possível explorar dois aspectos de campos matemáticos diferentes, abordamos o campo das grandezas e medidas em que propomos que os estudantes identificassem o transferidor como instrumento de medida assim como é proposto pelos parâmetros (PCPE) e o campo da geometria em que os estudantes deveriam identificar a conservação dos ângulos nas figuras. Com isto podemos perceber que através dessa situação didática proposta é possível explorar conceitos de diferentes campos matemáticos. 
Nesse contexto, essa discussão não se encerra por aqui, podendo gerar outras pesquisas. De modo que se possa utilizar um maior espaço de tempo durante a aplicação do projeto, pois contribuirá para que os estudantes se familiarizem com o objeto matemático e com o objeto de estudo. Essa oportunidade facilitará para que o aluno compreenda o conceito de forma que além de estruturar mentalmente, possa expressar seu entendimento de forma escrita e com rigor matemático. Uma outra sugestão seria propor a situação em níveis mais avançados, como $8^{\circ}$ e $9^{\circ}$ anos e investigar o desenvolvimento desses estudantes, que possivelmente já utilizaram o conceito de ângulos nos anos anteriores, como também os outros conceitos inerentes a construção.

\section{Referências}

ALMOUloud. Saddo Ag. Fundamentos da Didática da Matemática / Saddo Ag Almouloud. - Curitiba: Ed. UFPR, 2007.

BRASIL. Ministério da educação. Base Nacional Comum Curricular. Brasília, DF: MEC, 2017. Disponível em: <http://basenacionalcomum.mec.gov.br/download-da-bncc> Acesso em: 25 Mai. 2018.

BRASIL. Lei de Diretrizes e Bases da educação nacional. Lei $n^{\circ}$ 9.394, de 20 de dezembro de 1996.

BROUSSEAU, Guy. Introdução ao estudo das situações didáticas: conteúdos e métodos de ensino / Guy Brousseau ; apresentação de Benedito Antonio da Silva; consultoria técnica José Carlos Miguel ; [tradução Camila Bógea\}. - São Paulo : Ática, 2008.

FIORENTINI, Dario. MIORIM, Maria Ângela. Uma reflexãosobre o uso de materiais concretos e jogos no ensinoda Matemática -Texto extraído do Boletim da SBEM-SP, n. 7, de julho-agosto de 1990.

GODOY, Arilda Schmidt. Introdução à pesquisa qualitativa e suas possibilidades. RAE Revista de Administração de Empresas, São Paulo, v. 35, n. 2, p. 57-63,1995.

GONÇALVES, Claúdia Juliana Fanelli. Texto complementar - o uso do quebra - cabeças no aprendizado de conceitos geométricos. - Maringá: Ed. UEM, 2013.

MAZIERO, Lieth Maria. Quadriláteros: Construções geométricas com o uso do compasso. Mestrado profissional em matemática. Pontifícia universidade católica de São Paulo-PUC/SP. São Paulo, 2011.

PERNAMBUCO. Parâmetros curriculares para a Educação BásicaDo Estado de Pernambuco - Concepções. 2012. 